\title{
Oestrogen-induced androgen insufficiency results in a reduction of proliferation and differentiation of spermatogonia in the zebrafish testis
}

\author{
Paul P de Waal ${ }^{1}$, Marcelo C Leal ${ }^{1,2}$, Ángel García-López ${ }^{1}$, Sergio Liarte ${ }^{3}$, Hugo de Jonge ${ }^{1}$, \\ Nathalie Hinfray ${ }^{4}$, François Brion ${ }^{4}$, Rüdiger W Schulz ${ }^{1,5}$ and Jan Bogerd ${ }^{1}$ \\ ${ }^{1}$ Division of Endocrinology and Metabolism, Department of Biology, Faculty of Science, Utrecht University, Hugo R Kruyt Building, Padualaan 8, $3584 \mathrm{CH}$ \\ Utrecht, The Netherlands \\ ${ }^{2}$ Laboratory of Cellular Biology, Department of Morphology, Institute of Biological Sciences, Federal University of Minas Gerais, Belo Horizonte MG 31270-901, \\ Brazil \\ ${ }^{3}$ Department of Cell Biology, Faculty of Biology, University of Murcia, 30100 Murcia, Spain \\ ${ }^{4}$ Unité d'évaluation des risques écotoxicologiques, Direction des Risques Chroniques, Institut National de l'Environnement Industriel et des Risques (INERIS), \\ BP 2, F-60550 Verneuil-en-Halatte, France \\ ${ }^{5}$ Research Group Reproduction and Growth, Institute of Marine Research, PO Box 1870, Nordnes, 5817 Bergen, Norway \\ (Correspondence should be addressed to J Bogerd or R W Schulz at Division of Endocrinology and Metabolism, Department of Biology, Faculty of Science, \\ Utrecht University; J Bogerd; Email: j.bogerd@uu.nl, R W Schulz; Email: r.w.schulz@uu.nl)
}

\begin{abstract}
Androgens can induce complete spermatogenesis in immature or prepubertal teleost fish. However, many aspects of the role of androgens in adult teleost spermatogenesis have remained elusive. Since oestrogens inhibit androgen synthesis, we used an oestrogen-induced androgen depletion model to identify androgen-dependent stages during adult zebrafish spermatogenesis. Exposure to $10 \mathrm{nM} 17 \beta$-oestradiol $\left(\mathrm{E}_{2}\right)$ in vivo at least halved the mass of differentiating germ cells (from type B spermatogonia to spermatids), while type A spermatogonia accumulated. Studies on the cellular dynamics revealed that a reduction of spermatogonial proliferation together with an inhibition of their differentiation to type B spermatogonia were the basis for the oestrogen-mediated disturbance of spermatogenesis. The capacity of the zebrafish testis to produce
\end{abstract}

11-ketotestosterone as well as the expression of steroidogenesis-related genes was markedly decreased after in vivo oestrogen exposure. Moreover, the androgen-release response to recombinant zebrafish Lh was lost after oestrogen exposure. We conclude that oestrogen exposure caused a state of androgen insufficiency in adult male zebrafish. Since the downregulation of the steroidogenic system as well as the disturbance of spermatogenesis in testicular explants exposed to $\mathrm{E}_{2}$ ex vivo was much less severe than after in vivo exposure, the main inhibitory effect appears to be exerted via feedback inhibition of gonadotropin release. This experimental set-up helped to identify spermatogonial proliferation and their differentiation as androgen targets in adult zebrafish spermatogenesis.

Journal of Endocrinology (2009) 202, 287-297

\section{Introduction}

Oestrogen signalling is involved in many processes in male reproduction, and is essential to achieve normal fertility, as indicated in mammals in studies conducted with oestrogen receptor (ER) knockout mice (Eddy et al. 1996, Hess et al. 2000, Akingbemi et al. 2003, Gould et al. 2007). Furthermore, oestrogenic feedback on the hypothalamus and pituitary controls the synthesis and release of gonadotropins in mammals, and hence the testicular synthesis of androgens (Jong et al. 1975, Lindzey et al. 1998, Turner et al. 2000). Leydig cells express ER (Zhou et al. 2002), and direct oestrogenic inhibition of steroidogenesis has been reported as well (Bartke et al. 1977).

Three types of ER exist in fish, namely ER $\alpha, E R \beta 1$ and ER $\beta 2$ (Hawkins et al. 2000, Menuet et al. 2002, Choi \& Habibi 2003, Halm et al. 2004, Filby \& Tyler 2005); the types are designated as, (gene/protein) esr1/Esr1, esr2b/Esr2b and esr $2 a /$ Esr2a respectively, following the Official Zebrafish Nomenclature Guidelines (http://zfin.org). All types of ER are expressed in testis (Hawkins et al. 2000, Menuet et al. 2002, Choi \& Habibi 2003, Halm et al. 2004, Filby \& Tyler 2005). Studies describing their cellular localization in testis indicate a heterogeneous pattern of mRNA and protein expression, for example, Esr1 protein has been found in the interstitial tissue of rainbow trout (Oncorhynchus mykiss) testis (Bouma \& Nagler 2001), esr1 and esr2 mRNA expressions were found in Japanese common goby (Acanthogobius flavimanus) and Japanese eel (Anguilla japonica) Sertoli cells (Miura et al. 1999, Ito et al. 2007), while Esr1 and Esr2 proteins were produced by meiotic and postmeiotic germ cells in channel catfish (Ictalurus punctatus) testis (Wu et al. 2001). Functionally, oestrogens stimulate spermatogonial stem cell renewal in immature Japanese eel 
testis probably via Sertoli cells (Miura et al. 1999, 2003). In amphibians, which have a cystic organization of spermatogenesis similar to fish, oestrogens promote proliferation of spermatogonia (Minucci et al. 1997, Cobellis et al. 1999, Chieffi et al. 2000).

Previous studies have reported detrimental effects of oestrogenic compounds on fertility at all levels of the brainpituitary-gonad axis in teleost fish (Tsai et al. 2005, Filby et al. 2006, Zhang et al. 2008), including impairment of spermatogenesis (Van der Ven et al. 2003, 2007, Van den Belt et al. 2004, Pawlowski et al. 2004), and inhibition of androgen synthesis, either directly on Leydig cells (Loomis \& Thomas 2000, Govoroun et al. 2001, Baron et al. 2005) or via feedback on hypothalamus and pituitary to control synthesis and release of gonadotropins (Dickey \& Swanson 1998, Kobayashi et al. 2001, Huggard-Nelson et al. 2002, Banerjee \& Khan 2008). However, it is not known exactly which step(s) in the developmental sequence constituting spermatogenesis is/are affected by oestrogens in fish. This may be partially related to the fact that quantitative morphometry has not yet been applied to the evaluation of oestrogenic treatment effects on fish testis.

Our present knowledge on the role of androgens in fish spermatogenesis is mainly based on studies conducted in prepubertal individuals. In immature Japanese eel testis containing type A and a few type B spermatogonia only, androgens can induce rapid proliferation of spermatogonia and their terminal differentiation into spermatozoa under tissue culture conditions (Miura et al. 1991). Androgen treatment of juvenile male African catfish (Clarias gariepinus) induced precocious testis growth, spermatogonial proliferation and entry into meiosis (Cavaco et al. 1998), and the rise of androgen plasma levels in pubertal Chinook salmon (Oncorhynchus tshawytscha) coincided with the start of rapid spermatogonial proliferation (Campbell et al. 2003). However, scarce information is available on the role of androgens in adult spermatogenesis in fish. In mammals, it is well known that the first (pubertal) wave of spermatogenesis differs from adult spermatogenesis in both regulation and timing; for example, androgen requirements differ between pubertal start and adult maintenance of spermatogenesis (Handelsman et al. 1999).

An oestrogen-induced decrease of testosterone levels has given valuable information on androgen-dependent stages in rodent spermatogenesis, revealing a slower conversion of round to elongated spermatids (O'Donnell et al. 1994). A similar approach was used in the current report to investigate the role of androgens in adult fish spermatogenesis. We studied androgen release and expression of steroidogenesis-related genes in the testis of adult zebrafish (Danio rerio) after exposure to $17 \beta$-oestradiol $\left(\mathrm{E}_{2}\right)$ in vivo, and in zebrafish testicular tissue exposed to $\mathrm{E}_{2}$ ex vivo. Moreover, we determined the changes in absolute weight of the different germ cell stages and we quantified germ cell proliferation and apoptosis.

\section{Material and Methods}

\section{Fish stocks}

Unless otherwise stated, adult ( $>90 \mathrm{dpf}$ ) male Tübingen AB strain zebrafish were used for experimental purposes in the current study. Animal culture, performed using standard conditions for this species (Westerfield 2000), handling and experimentation were consistent with the Dutch national regulations, and were approved by the Life Science Faculties Committee for Animal Care and Use in Utrecht (The Netherlands).

\section{In vivo exposure to $E_{2}$}

Male zebrafish were exposed to either $0.3 \mathrm{nM} \mathrm{E}_{2}$ (SigmaAldrich), $10 \mathrm{nM} \mathrm{E}$, or control conditions (same volume of deionized water only; see below) for either 6 or 21 days during in vivo exposure experiments. The dose of $0.3 \mathrm{nM}$ was chosen since it is close to the $K_{\mathrm{d}}$-values of the zebrafish Esr proteins (Menuet et al. 2002), while the dose of $10 \mathrm{nM}$ was selected based on its reported capacity to disturb adult zebrafish spermatogenesis (Van der Ven et al. 2003). Since $0 \cdot 3 \mathrm{nM} \mathrm{E}_{2}$ did not elicit any deleterious effect on spermatogenesis after 21 days of exposure (see Suppl. Figure S1, see Supplementary data in the online version of the Journal of Endocrinology at http://joe.endocrinology-journals.org/content/vol202/ issue2/), we decided to continue our studies with the $10 \mathrm{nM}$ dose only. Sample sizes for the different experiments or types of analyses varied from 4 to 13 fish per treatment (see respective figure legends). A $10 \mu \mathrm{M} \mathrm{E} \mathrm{E}_{2}$ stock solution was prepared in deionized water by extensive stirring at $40^{\circ} \mathrm{C}$, which was then further diluted to $10 \mathrm{nM}$ in aquarium water. Exposure was performed in glass tanks containing 18 liters water maintained at $27 \cdot 1 \pm 0 \cdot 2{ }^{\circ} \mathrm{C}$ under constant aeration. Fish were transferred to the experimental tanks $24 \mathrm{~h}$ before initiating each exposure period. The exposure environment was refreshed everyday by moving the fish to a second set of identically prepared tanks. After exposure, fish were euthanized in ice water and total body weight was measured. Both testes of each animal were excised, weighed and the gonadosomatic index (GSI; i.e. the ratio between testis weight and body weight) was calculated. Testis samples were used for acute ex vivo steroid release bioassays or processed for histological evaluation, morphometrical quantification, immunohistochemistry, Western blot or gene expression analysis (for detailed experimental procedures, see Supplemental Information, see Supplementary data in the online version of the Journal of Endocrinology at http://joe. endocrinology-journals.org/content/vol202/issue2/).

\section{Ex vivo exposure to $E_{2}$}

To determine whether oestrogens are able to exert direct effects on zebrafish spermatogenesis and testicular androgen production, an ex vivo organ culture system for zebrafish 
testis was used (Leal et al. 2009a). In this system, the influence of interindividual variation is reduced by incubating the two testes of each fish in parallel, such that one testis served as control for the contra-lateral one. Basal culture medium was supplemented with $50 \mathrm{ng} / \mathrm{ml}$ recombinant gilthead seabream (Sparus aurata) insulin-like growth factor 1 (Igf1; Prospec-Tany Technogene, Rehovot, Israel), which was added to support spermatogenesis in an androgen-independent manner (Leal et al. 2006). This setting was chosen to study the direct effects of $E_{2}$ on the testicular steroidogenic system while avoiding dramatic changes in the cellular composition of the testis explant in the absence of compounds supporting spermatogenesis (Leal et al. 2009a). The $\mathrm{E}_{2}$ stock solution used in these experiments was prepared as described above. Incubation took place in a humidified air atmosphere at $25^{\circ} \mathrm{C}$, and medium was refreshed every 3-4 days. When androgen release by testicular tissue was to be measured, the culture environment was refreshed with the same frequency by transferring the nitrocellulose membranes supporting the tissue explants to fresh culture wells (and both medium and agarose blocks were stored together at $-25^{\circ} \mathrm{C}$ ). After incubation (exposure periods are specified for each experiment performed; see below), testis tissue explants were collected, weighed and processed for morphological evaluation or gene expression analysis (for detailed experimental procedures, see Supplemental Information), while both medium and agarose blocks were stored together at $-25{ }^{\circ} \mathrm{C}$ for quantification of 11-ketotestosterone (11-KT) levels by RIA (Schulz et al. 1994). For that purpose, incubation media and agarose cylinders were transferred to a glass tube for homogenization (Ultra-turrax T25; Janke \& Kunkel Ika-Labortechik, Staufen, Germany) and steroid extraction with diethyl ether (four times with $5 \mathrm{ml}$ solvent each). Recovery studies using tritiated androgens showed that only the steroids in the incubation medium, but not those associated with the agar cylinder, were effectively extracted, resulting in a relatively low recovery of $47 \pm 1 \% \quad(n=8)$. The results were corrected accordingly, and are expressed as pg 11-KT released per mg of testis tissue incubated.

In a first series of experiments, testicular tissue explants

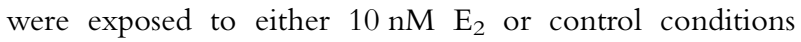
(basal medium only) for either $30 \mathrm{~h}$ (studies on steroid release only; $n=9$ explants per treatment), 6 days (studies on steroid release, morphology and gene expression; $n=6-9$ explants per treatment) or 12 days (studies on morphology only; $n=6-9$ explants per treatment). The $30 \mathrm{~h}$ incubation period was selected based on our recent studies showing that after $48 \mathrm{~h}$ under basal conditions, the activity of the steroidogenic system had decreased to $<10 \%$ of the starting level while at $30 \mathrm{~h}$ the responsiveness to an acute stimulation was intact (Leal et al. 2009a). The 6 and 12 days incubation periods were selected in order to evaluate possible medium- to long-term effects of $\mathrm{E}_{2}$ on zebrafish spermatogenesis.
In a second series of experiments, testicular tissue explants were exposed to $0.5 \mu \mathrm{M}$ of the adenylate cyclase activator forskolin (prepared in DMSO; Sigma-Aldrich) alone or in the presence of $10 \mathrm{nM} \mathrm{E}_{2}$ for 6 days (studies on steroid release and gene expression; $n=8$ explants per treatment). This experimental setting was chosen according to recent studies demonstrating the capacity of forskolin to partially prevent down-regulation of the zebrafish testicular steroidogenic system under culture conditions (Leal et al. 2009a), which allowed examination of possible, direct effects of $E_{2}$ on the activity of the steroidogenic system in a medium-term time frame.

\section{Acute ex vivo steroid release bioassays}

The steroidogenic capacity of testicular tissue after 6 days of in vivo oestrogen exposure was evaluated using an acute ex vivo steroid release bioassay previously described for African catfish (Schulz et al. 1994) and adapted for zebrafish testis explants. For this experiment, adult outbred zebrafish were used. The testes of either $10 \mathrm{nM} \mathrm{E}_{2}$-treated or control fish $(n=10-12$ fish per group) were collected after a 6 day in vivo oestrogen exposure period and the two testes were immersed in D-PBS + . One testis was incubated in basal medium (the same as used for ex vivo exposure to $\mathrm{E}_{2}$, but excluding retinoic acid and Igf1), serving as control for the contra-lateral testis, which was challenged with either $0.5 \mu \mathrm{M}$ forskolin or a $1 / 10$ dilution of single-chain, recombinant zebrafish Lh stock solution (preparation of recombinant zebrafish Lh is described in Supplemental Information). Testis tissue was immersed in $200 \mu \mathrm{l}$ medium in 96-well flat-bottom plates (Corning Inc., New York, NY, USA) in a humidified air atmosphere at $25{ }^{\circ} \mathrm{C}$ for $18 \mathrm{~h}$. After incubation, testis explants were weighed and discarded, and the incubation medium was heated at $80^{\circ} \mathrm{C}$ for $1 \mathrm{~h}$, centrifuged for $30 \mathrm{~min}(16000 \mathrm{~g}$; $4{ }^{\circ} \mathrm{C}$ ) and the supernatant was stored at $-25^{\circ} \mathrm{C}$ until direct quantification (i.e. without extraction) of $11-\mathrm{KT}$ levels by RIA as reported (Schulz et al. 1994). The results were expressed as pg 11-KT released per mg of testis tissue incubated.

\section{Statistical analysis}

For the in vivo experiments, differences between treatments were analysed by the Student $t$-test with two-tailed $P$ value (in some cases, data were log transformed to achieve an equal variance), except for the gene expression analysis after 21 days in vivo $\mathrm{E}_{2}$ exposure in which, due to differences in the number of individuals between groups, the Mann-Whitney nonparametric test was used. Comparison of groups in the acute 11-KT release assay for both in vivo and ex vivo experiments was done with one-way ANOVA followed by the StudentNewman-Keuls test. For the ex vivo gene expression experiments, differences between treatments were tested for statistical significance using the paired $t$-test (when necessary, 
data were $\log$ transformed to achieve an equal variance). A significance level $(P)$ of 0.05 was applied in all the statistical analyses, which were performed using the Prism4 software package (GraphPad software, San Diego, CA, USA).

\section{Results}

Effects of in vivo exposure to $E_{2}$ on zebrafish testicular physiology

In vivo exposure to oestrogen, either for 6 or 21 days, did not induce significant changes in body weight or GSI (data not shown), while the decrease in total testis weight (from $6 \cdot 21 \pm 0.54$ to $4 \cdot 68 \pm 0.32 \mathrm{mg}$ ) observed after 21 days reached statistical significance.

Qualitative morphological (Fig. 1A-C) and quantitative morphometric analysis (Fig. 1D and E) of testis tissue samples collected after both 6 and 21 days in vivo exposure to $\mathrm{E}_{2}$ revealed a significant inhibitory effect on zebrafish spermatogenesis. On day 6 the main changes in the morphometric analysis were recorded among type $\mathrm{B}$ spermatogonia, primary spermatocytes, and secondary spermatocytes, which decreased to $54-60 \%$ of control levels (Fig. 1D). After 21 days of oestrogen exposure, the mass of type B spermatogonia, primary and secondary spermatocytes and spermatids decreased further and significantly (e.g. down to $\sim 19 \%$ of control levels in the case of spermatids), whereas the mass of type A spermatogonia increased to $\sim 220 \%$ of control levels (Fig. 1E). Expression levels of synaptonemal complex protein 3 like (sycp3l) mRNA, a zebrafish homologue to a marker for primary spermatocytes (De la Fuente et al. 2007), correlated well with the reported decrease in the presence of primary spermatocytes in zebrafish testis after in vivo $\mathrm{E}_{2}$ exposure (Fig. 1F). No differences were observed in the mass of spermatozoa or other cell types between treatment groups at both sampling times (Fig. 1D and E). A very low incidence of apoptotic germ cells (strongly condensed, darkly stained nuclei in toluidine-blue-stained sections), and no difference between control and $\mathrm{E}_{2}$-treated groups at both sampling times were observed by morphometrical analysis (Fig. 1D and E).

Searching for a mechanistic basis for the reduced mass of type B spermatogonia and spermatocytes, immunocytochemical detection of the $\mathrm{G}_{2}$-phase cell cycle marker phosphorylated histone $\mathrm{H} 3$ (PH3) was used to assess proliferative activity after 6 days of $E_{2}$ exposure. As shown in Suppl. Figure S2 (see Supplementary data in the online version of the Journal of Endocrinology at http://joe. endocrinology-journals.org/content/vol202/issue2/), proliferating (i.e. PH3-positive) single spermatogonia, as well as cysts containing four or more proliferating germ cells (spermatogonia or spermatocytes), were found in greater numbers on sections from control than from $\mathrm{E}_{2}$-treated testes. Quantification of this observation showed that treatment with $\mathrm{E}_{2}$ reduced the number of proliferating single germ cells as well as cysts of spermatogonia/spermatocytes significantly (to $\sim 53$ and $\sim 37 \%$ of control levels respectively; Fig. $1 \mathrm{G}$ ).
We then examined the assumption that in vivo oestrogen exposure inhibited the testicular steroidogenic system. We quantified mRNA and protein levels of cytochrome P450 17 $\alpha$-hydroxylase/17-20-lyase (cyp17a1/Cyp17a1), a steroidogenic enzyme required for androgen production, the mRNA amounts of steroidogenic acute regulatory protein $($ star $)$, the protein controlling the rate-limiting step in steroidogenesis (i.e. the transfer of cholesterol from the outer to the inner mitochondrial membrane), as well as the mRNA amounts of both gonadotropin receptors (Lh receptor, $l h r$; and Fsh receptor, $f$ shr $r$. Moreover, we challenged testis explants from animals exposed to oestrogen for 6 days in vivo with stimulators of steroid release. After 6 days of $\mathrm{E}_{2}$ exposure, $l h r \mathrm{mRNA}$ levels increased significantly (to $155 \%$ of control levels), while no significant changes were observed in $f$ shr mRNA levels. The levels of both star and cyp17a1 mRNA diminished to 50 and 14\% of control levels respectively (Fig. 2A). Both western blotting of testis tissue homogenates (inset Fig. 2B and C) and immunohistochemical detection in tissue sections (Fig. 2B and C) demonstrated a clear down-regulation of the levels of Cyp17a1 protein, which is exclusively expressed in Leydig cells. Twenty-one days of oestrogen exposure resulted in strong decreases in the mRNA levels of $t h r$ (to $\sim 1 \%$ ), $f$ shr (to $\sim 10 \%$ ) and star (to $\sim 6 \%$ ) (Fig. 2A). Levels of cyp17a1 mRNA could not be measured at 21 days due to technical problems, although a similarly strong downregulation should be expected. After 6 days in vivo exposure to $\mathrm{E}_{2}$, acute ex vivo androgen release was significantly downregulated between $\sim 2.6$ and $\sim 9.9$ fold in all the conditions assayed (i.e. basal, forskolin- and Lh-stimulated); oestrogenexposed testis explants maintained a limited steroidogenic response to forskolin $(P<0 \cdot 05)$, but not to recombinant zebrafish Lh (Fig. 2D).

\section{Effects of ex vivo exposure to $E_{2}$ on zebrafish testicular physiology}

Morphological evaluation of testicular tissue explants exposed to $\mathrm{E}_{2}$ for 6 and 12 days ex vivo revealed no clear disruptive effect on spermatogenesis (data not shown), in contrast to the results obtained in the testes of in vivo $\mathrm{E}_{2}$-exposed fish. With regards to gene expression, however, $t h r$ mRNA levels showed an increase (to 184\% of control levels; Fig. 3A) after 6 days of ex vivo exposure to $E_{2}$, as observed after 6 days of in vivo exposure, while mRNA amounts of $f$ shr decreased (to $65 \%$ of control levels; Fig. 3A). Also the mRNA levels of star and cyp 17a1 were decreased to almost half of control levels (Fig. 3A) and responded similarly as in the in vivo experiments, though not as prominently for $c y p 17 a 1$. However, it should be noted that the steroidogenic system undergoes a spontaneous downregulation under ex vivo culture conditions, reflected by a decrease in cyp17a1 and star mRNA levels (Leal et al. 2009a). Hence, it seems more appropriate to state that $E_{2}$ further enhanced the spontaneous downregulation of star and cyp17a1 mRNA levels observed ex vivo (Fig. 3A, 


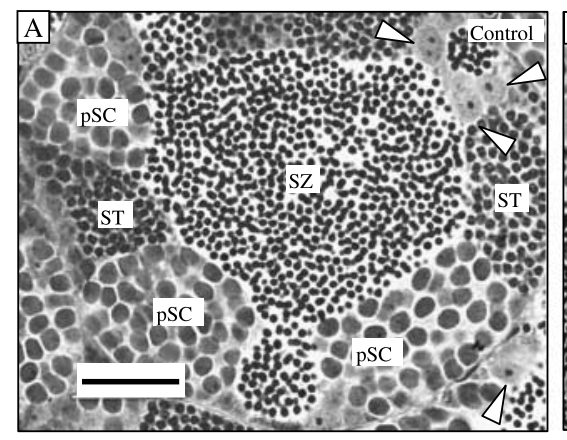

$\mathrm{D}$

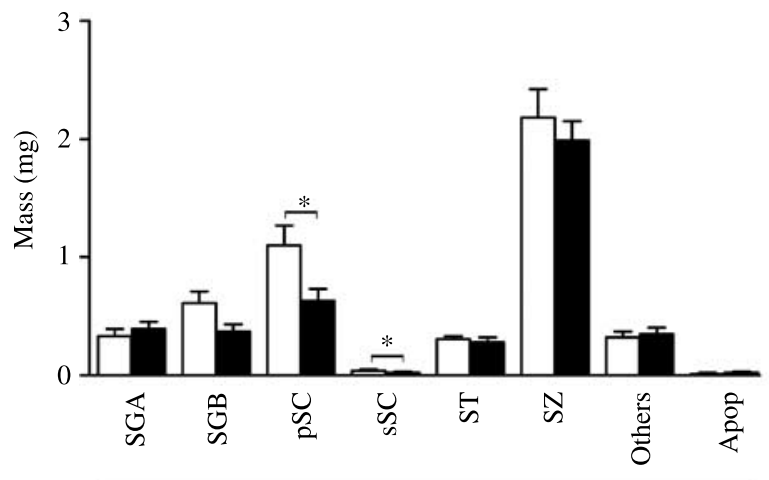

6 days

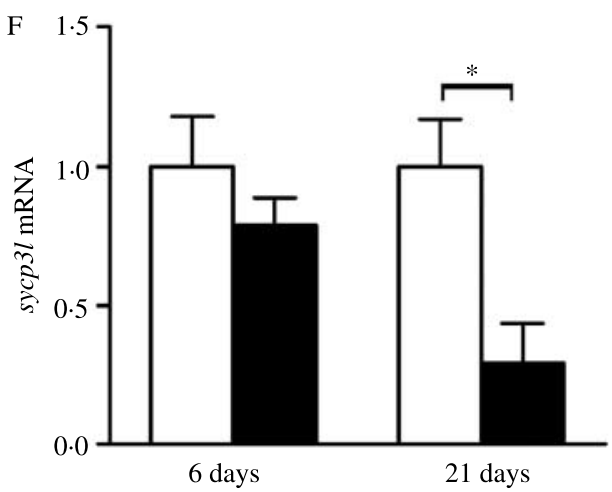

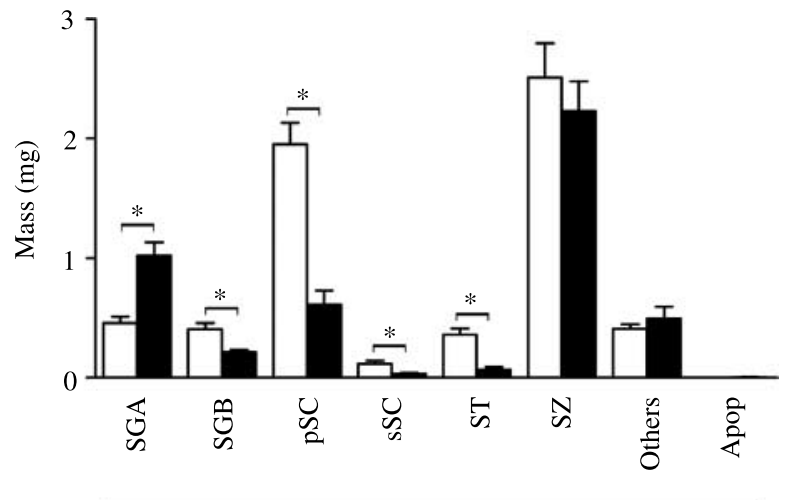

21 days

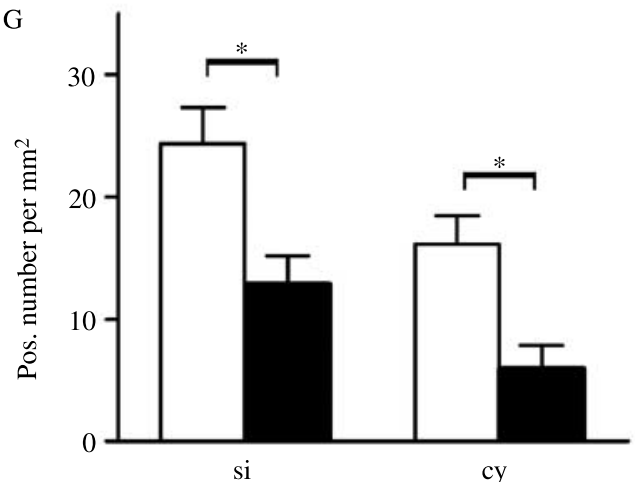

$\mathrm{E}_{2}$

Figure 1 Zebrafish testicular physiology after exposure to $10 \mathrm{nM} \mathrm{E}_{2}$ in vivo. Zebrafish testis sections from control fish (A), or from $\mathrm{E}_{2}$-treated fish 6 days (B) or 21 days (C) after the start of exposure. Morphometric analysis ( $n=5-7$ fish per group) of zebrafish testis sections, presenting data as mass (mg) of testicular cell types, 6 days (D) or 21 days (E) after the start of exposure to 10 nM $E_{2}$. (F) Relative amounts of sycp3l mRNA, normalized to $18 \mathrm{~S} r R N A$, in control and $\mathrm{E}_{2}$-exposed males ( $n=6-13$ fish per treatment). (G) Germ cell proliferation after 6 days of $\mathrm{E}_{2}$ exposure ( $n=4$ fish per treatment). Phosphohistone H3 (PH3)-positive number of single nuclei of type A spermatogonia (si) and cysts (cy) containing $\geq 4 \mathrm{PH} 3$-positive nuclei of spermatogonia/spermatocytes per $\mathrm{mm}^{2}$ were counted. Arrowheads and SGA, type A spermatogonia; SGB, type B spermatogonia; pSC, primary spermatocytes; sSC, secondary spermatocytes; ST, spermatids; SZ, spermatozoa; apop, apoptotic cells. Bars marked with * are significantly different from their respective controls $(P<0 \cdot 05)$. Scale bars in $(A)$, (B) and $(C)=25 \mu \mathrm{m}$.

left panel). However, the continuous presence of $0.5 \mu \mathrm{M}$ forskolin (Fig. 3A, right panel) reduced the additional downregulatory effect of $\mathrm{E}_{2}$ on star mRNA levels, while it abolished such an effect on $c y p 17 a 1$ mRNA levels.
After $30 \mathrm{~h}$ of tissue culture ex vivo and during the first three days in the continuous presence of forskolin, there was no change in the cumulative testicular release of 11-KT between groups incubated in the absence or presence of $\mathrm{E}_{2}$ (Fig. $3 \mathrm{~B}$, 

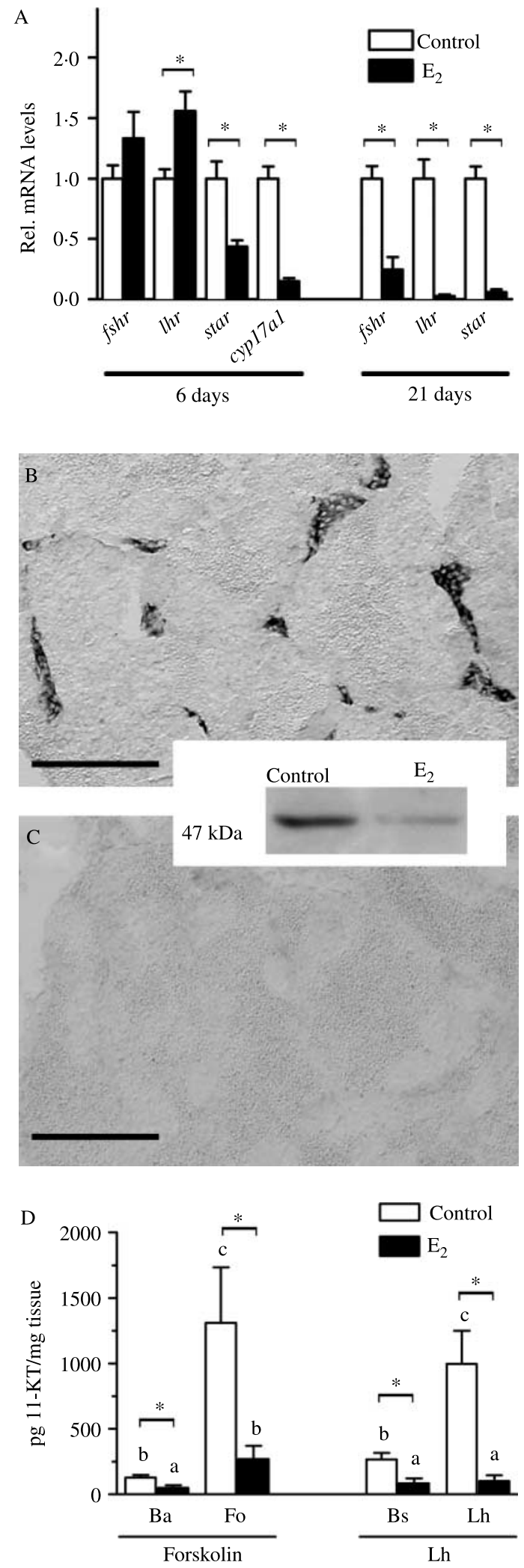

Journal of Endocrinology (2009) 202, 287-297 left and middle panel). Despite the protective effect of forskolin on $\mathrm{E}_{2}$-induced down-regulation of star and cyp 17a1 mRNA levels, ex vivo exposure to $\mathrm{E}_{2}$ for 6 days was reflected in a significantly lower amount of $11-\mathrm{KT}$ released from culture days 3 to 6 (Fig. 3B, right panel).

\section{Discussion}

Our data demonstrates oestrogen-induced disruption of the spermatogenic process in adult zebrafish. Previous studies reported similar disruptive effects of oestrogens on the testis of sexually mature zebrafish (Van der Ven et al. 2003, 2007, Van den Belt et al. 2004) and other teleost species (e.g. Kinnberg \& Toft 2003, Pawlowski et al. 2004, Chaves-Pozo et al. 2007), but the precise stage of inhibition of spermatogenesis was not determined. Therefore, the mechanistic basis of oestrogen-induced disruption of germ cell development in adult male teleost testis has remained unclear.

Different from earlier stereological analyses on testes of $E_{2}$-exposed zebrafish (Van der Ven et al. 2003, ChristiansonHeiska et al. 2004) or guppy (Poecilia reticulata; Nielsen \& Baatrup 2006), a distinction was made in the spermatogonial compartment between early (type A) and late (type B) spermatogonia in the current study (see Leal et al. 2009b, for a comprehensive description of the spermatogonial generations in zebrafish). Implementation of this distinction, quantification of the absolute masses of the different germ cell types, and analysis of germ cell proliferation and apoptosis enabled us to pinpoint the stages of spermatogenesis affected by the oestrogen treatment. Thus, $\mathrm{E}_{2}$ exposure resulted in two main effects: i) the reduction, but not the abolishment, of proliferation of type $A$ and type $B$ spermatogonia as demonstrated by quantifying PH3-positive germ cells, and ii) the blockade of differentiation of type $A$ into type B spermatogonia, as demonstrated by the accumulation (i.e. increased mass) of type A spermatogonia. Jointly, these effects resulted in a depletion of developmental stages beyond type A spermatogonia, as demonstrated by the significant

Figure 2 Steroidogenic capacity of zebrafish testis after exposure to $10 \mathrm{nM} \mathrm{E}_{2}$ in vivo. (A) Relative mRNA levels of fshr, Ihr, star and cyp 17a 1 after either 6 or 21 days of $E_{2}$ exposure $(n=6-13$ fish per group). Data are shown as relative values of respective transcript amounts measured in control fish. Cyp17a1 immunodetection on transversal zebrafish testis cryosections obtained from (B) control fish and $(C) E_{2}$-exposed fish. The inset between $B$ and $C$ shows Cyp17a1 protein amounts detected by Western blot in testicular lysates obtained from both treatment groups. (D) Ex vivo acute androgen release in the absence (Ba, basal) or presence of either $0.5 \mu \mathrm{M}$ forskolin (Fo) or recombinant zebrafish Lh by zebrafish testis tissue obtained from fish exposed to $\mathrm{E}_{2}$ in vivo for 6 days $(n=5-6$ fish per treatment). Androgen release is expressed as amount of 11-KT produced per unit weight of testis tissue incubated. Bars marked with $*$ are significantly different from their respective controls $(P<0 \cdot 05)$. For each compound in panel (D), different letters denote statistical differences $(P<0 \cdot 05)$. Scale bars in (B) and $(C)=100 \mu \mathrm{m}$. 

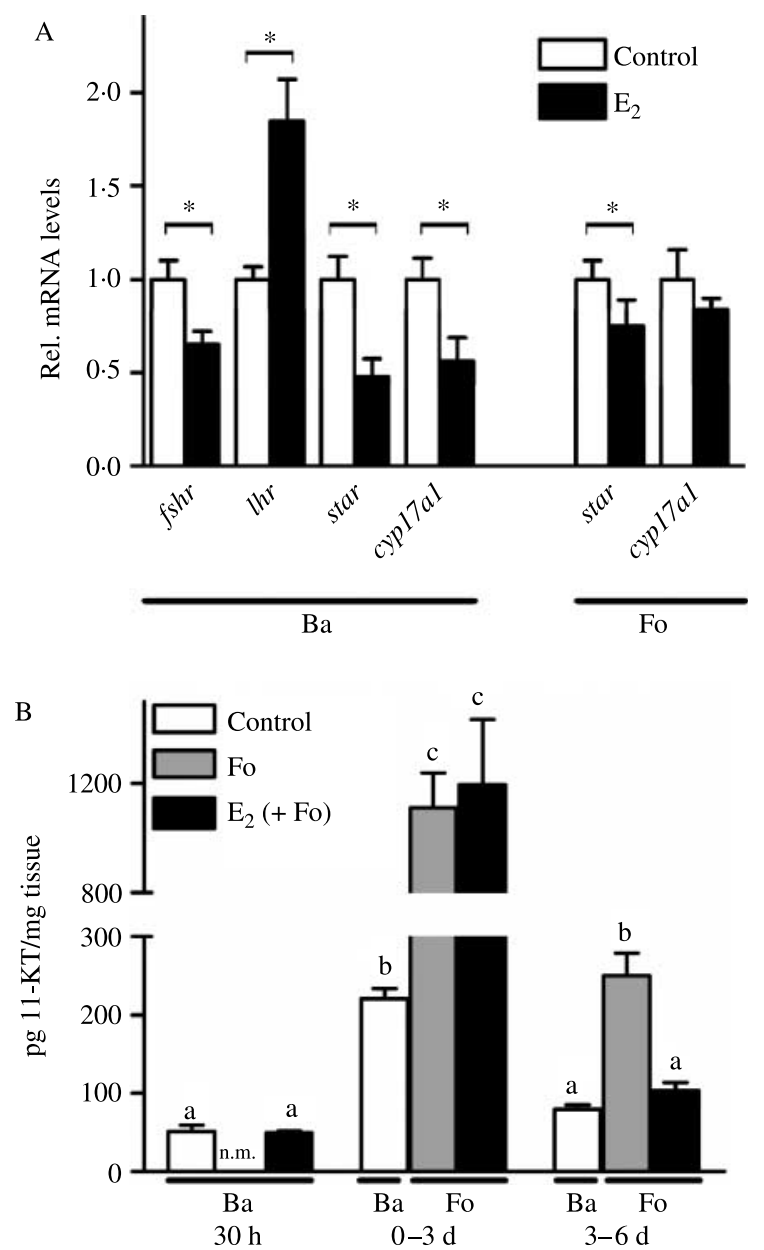

Figure 3 Steroidogenic capacity of zebrafish testis after exposure to $10 \mathrm{nM} \mathrm{E}_{2}$ ex vivo. (A) Relative mRNA levels of fshr, Ihr, star and cyp17a1 after 6 days of $\mathrm{E}_{2}$ ex vivo exposure either in the absence (Ba, basal) or the presence of $0.5 \mu \mathrm{M}$ forskolin (Fo) $(n=8$ explants per group). Data are shown as relative values of respective transcript amounts measured in control fish. (B) Cumulative androgen release after ex vivo $\mathrm{E}_{2}$ exposure for $30 \mathrm{~h}$ under basal conditions and for 3 or 6 days (release was measured from 0 to 3 and from 3 to 6 days) in the absence or presence of $0.5 \mu \mathrm{M}$ forskolin $(n=8$ explants per group). Androgen release is expressed as amount of 11-KT produced per unit weight of testis tissue incubated. In panel (A), bars marked with* are significantly different from their respective controls, while different letters denote statistical differences in panel (B) $(P<0 \cdot 05)$. n.m., not measured.

decrease in the masses of type B spermatogonia, spermatocytes and spermatids. Germ cell depletion was increasingly prominent with their progressive differentiation (reductions to $53,31,31$ and $19 \%$ of control values for type B spermatogonia, primary, secondary spermatocytes, and spermatids respectively). This may indicate that oestrogenmediated inhibition of spermatogenesis is based on (at least) two components, the reduced availability of type B spermatogonia, as demonstrated in the present study, and inhibition of germ cell entry into or progress through meiosis and spermiogenesis. To clarify the second component, however, other experiments will be required. In any case, the absence of a clear inhibitory effect of oestrogen on meiosis/spermiogenesis ex vivo renders it unlikely that oestrogen affects these stages directly, while the presence of meiotic and spermiogenic stages shows that meiosis and spermiogenesis are compatible with elevated oestrogen concentrations in zebrafish.

Our results on oestrogen-mediated reduction of germ cell proliferation are in accordance with previous observations in fish and amphibian species (Song \& Gutzeit 2003, Tsai et al. 2005, Chaves-Pozo et al. 2007), although these studies did not determine the changes in germ cell masses (i.e. provided data on relative changes in the germ cell compartment), and did not always identify the specific stage of spermatogenesis affected. Interestingly, Miura et al. (2003) reported an $\mathrm{E}_{2}$-triggered molecular mechanism, which involves upregulation of platelet-derived endothelial cell growth factor, and subsequently stimulates self-renewal divisions of spermatogonial stem cells, the first generation of type A spermatogonia, in immature Japanese eel testis ex vivo. Although we found an increased mass of type A spermatogonia, this was associated with a reduced proliferation activity of these cells. In conjunction with no change in the low rate of apoptosis, this can be explained by a block of differentiation, and ensuing accumulation of type A spermatogonia. Therefore, juvenile eels may respond differently to oestrogens than adult zebrafish (see also below for a discussion on oestrogen feedback effects on the brain/pituitary level). Moreover, in eel testis ex vivo, the stimulatory effect decreased with increasing $(0 \cdot 01-1 \mathrm{ng} /$ ml) oestrogen doses (Miura et al. 1999), the concentration used in the present study being approximately three times higher than the maximum concentration used for eel testis.

Different from previous reports, where an increased incidence of germ cell apoptosis was proposed as an important cause for oestrogen-induced impairment of spermatogenesis in other fish species (Weber et al. 2004, Chaves-Pozo et al. 2007), our morphometric analysis could not confirm this observation for zebrafish.

Based on the data available from mammalian models (Bartke et al. 1977, Akingbemi et al. 2003, Gould et al. 2007), we hypothesized that oestrogen treatment inhibits androgen synthesis, thereby indirectly affecting spermatogenesis. Indeed, exposure of adult zebrafish to $\mathrm{E}_{2}$ in vivo suppressed the testicular steroidogenic capacity, as reflected by downregulation of key steroidogenesis-related genes (cyp17a1 and star) and the lower acute testicular 11-KT release (under basal conditions). Moreover, the $\mathrm{E}_{2}$ treatment suppressed the androgen release response to an acute gonadotropic stimulation with biologically active recombinant zebrafish Lh even though $l h r$ mRNA levels were elevated and $f s h r$ mRNA showed no significant changes after oestrogen treatment. These seemingly contradictory observations, which are reported for the first time in any fish species but have been previously reported in oestrogen-exposed mice (Fukuzawa et al. 2004), can be reconciled assuming that 
oestrogen exposure interfered with the signalling pathways activated by $\mathrm{Lh}$, but downstream of its receptor, in steroidogenic cells. Since forskolin, an activator of the adenylate cyclase, also induced a much weaker response in tissue from $\mathrm{E}_{2}$-treated fish than from control fish, we speculate that oestrogens may target one or more components of the $\mathrm{G} \alpha_{\mathrm{S}}$ - adenylate cyclase - protein kinase A (PKA) pathways. Therefore, we conclude that oestrogenic treatment induced a state of androgen-insufficiency in zebrafish by disturbing the testicular steroidogenic system at different levels, as previously suggested for other teleost fish species (Sohn et al. 1998, Loomis \& Thomas 2000, Andersen et al. 2006, Filby et al. 2006, Chaves-Pozo et al. 2007, Meier et al. 2007, Arukwe 2008, Blum et al. 2008, Jukosky et al. 2008, Zhang et al. 2008).

In search of a mechanism explaining the oestrogeninduced disruption at the testicular level, we thereafter studied possible direct effects of $\mathrm{E}_{2}$ on testis physiology using a recently developed tissue culture system for zebrafish testis explants (Leal et al. 2009a). After 6 days ex vivo oestrogen treatment, zebrafish testis showed significantly reduced star and $c y p 17 a 1 \mathrm{mRNA}$ levels as compared with control levels suggesting a direct inhibition of $\mathrm{E}_{2}$ on testicular steroidogenic system. However, it should be mentioned that the expression of steroidogenic enzymes, and thus the steroidogenic capacity, shows a spontaneous downregulation under prolonged ex vivo culture conditions (Baron et al. 2005, Leal et al. 2009a). Hence we further studied the ex vivo effects of $E_{2}$ exposure on the steroidogenic potential of zebrafish testis i) within the first $30 \mathrm{~h}$ of culture, when the zebrafish testicular steroidogenic system is still responsive to short-term acute stimulations, and thus can be considered relatively intact (Leal et al. 2009a), and ii) during 6 days of culture in the presence of forskolin, which partially prevents the aforementioned downregulation of the system under culture conditions, probably by upregulating the expression of several steroidogenesis-relevant genes through the cAMP/PKA pathway (Schwartz \& Roy 2000, Manna et al. 2003, Leal et al. 2009a). Under these culture conditions, oestrogen exposure was only able to decrease androgen release from day 3 to 6 possibly in association with the slight, but significant, downregulation of star mRNA transcription observed at the end of the incubation period. These results suggest that the direct effects exerted by oestrogens in the zebrafish testicular steroidogenic system may be relatively minor under the conditions tested in the current study, since $\mathrm{E}_{2}$ exposure could neither decrease androgen output when the system was still intact at $30 \mathrm{~h}$ of culture nor at 3 days of treatment. Previous studies in other fish and amphibian species, however, have reported significant inhibitory effects of oestrogenic compounds on both testicular androgen release and steroidogenic enzymes expression in tissue culture exhibiting, therefore, direct suppressive actions of oestrogens on testicular androgenesis (Pierantoni et al. 1986, Loomis \& Thomas 2000, Baron et al. 2005). Notably, such effects were only evident at very high oestrogen concentrations (>367 nM), making these results difficult to interpret in context with physiological oestrogen concentrations or to compare with our observations in the present study using $10 \mathrm{nM} \mathrm{E}_{2}$. In Atlantic croaker (Micropogonias undulatus), direct suppression of testicular androgen production by very high oestrogen concentrations $(>36.7 \mu \mathrm{M})$ was shown to be rapid (within $5 \mathrm{~min}$ ) and was transduced by a membrane-associated ER (Loomis \& Thomas 2000). Recently, a membrane associated ER, homologous to mammalian GPER, has been cloned from zebrafish, and is expressed in testis (Liu et al. 2009). The $E_{2}$ concentration used in the current study $(10 \mathrm{nM})$ could have been sufficient to activate the zebrafish Gper. However, the direct effects of oestrogen in the zebrafish testis were comparatively weak and possibly mediated via a nuclear Er, considering the prolonged time required for them to become evident, while the binding of $E_{2}$ to zebrafish Gper, although of high affinity $\left(K_{\mathrm{d}}=2 \cdot 8 \mathrm{nM}\right)$, was characterized by both rapid association and dissociation (Liu et al. 2009).

In contrast to the results obtained in the testes of $\mathrm{E}_{2}$-exposed zebrafish in vivo, morphological and/or morphometrical evaluation of testis tissue exposed to $E_{2}$ ex vivo revealed no clear disruption of spermatogenesis which, together with the minor direct effect exerted by oestrogen on the steroidogenic system, suggests that the $\mathrm{E}_{2}$-induced inhibitory effects on zebrafish testis functions mainly involve feedback mechanisms on the hypothalamus-pituitary system. Sex steroid, either androgens or oestrogens, feedback on gonadotropin synthesis and release is well established in fish (Dickey \& Swanson 1998, Kobayashi et al. 2001, Huggard-Nelson et al. 2002, Banerjee \& Khan 2008). In zebrafish, information on oestrogen effects on gonadotropin levels (either subunits mRNA expression levels or plasma levels) is scarce. Recently, Lin \& Ge (2009) described direct oestrogenic stimulation of $f h b$ and $l h b$ transcript levels in primary zebrafish pituitary cell culture, similar to previous findings in the closely related goldfish (Carassius auratus; Huggard-Nelson et al. 2002). While no information is available on in vivo oestrogen feedback effects on gonadotropin subunit mRNA levels in zebrafish, respective data (as well as gonadotropin plasma amounts) are available in goldfish. For this species, oestrogen treatment abolished the upregulation of both pituitary $f s h b$ mRNA levels and Lh plasma levels observed in ovariectomized individuals (Kobayashi et al. 2001). Furthermore, treatment of sexually mature goldfish with an ER antagonist increased circulating Lh levels (Billard \& Peter 1977). Finally, pre-treatment of late recrudescent goldfish of mixed sex with $E_{2}$ suppressed GnRH-mediated elevation of $f$ shb and thb expression both in vivo and in vitro (Huggard-Nelson et al. 2002). The latter has been reported recently in medaka (Oryzias latipes; Zhang et al. $2008)$ as well. These data indicate that $E_{2}$ inhibited the Gnrh/ Gnrh-receptor signalling system, and that these effects apparently overrule the direct, stimulatory effects of oestrogens on gonadotropin subunit expression. Also signalling pathways towards GnRH neurons, like $\gamma$-aminobutyric acid 
(Kah et al. 1992), or the recently described Kiss $1 / G p r 54$ system (Elizur 2009) may be influenced by estrogens in teleost fish. Therefore, $E_{2}$-induced gonadotropin insufficiency seems the main factor contributing to the observed downregulation of androgen production in the zebrafish testis, which in turn results in an interruption of spermatogenesis.

Androgen depletion or blocking of androgen signalling had a marked effect on meiotic and postmeiotic events of rodent spermatogenesis, whereas effects on spermatogonial proliferation were limited (O’Donnell et al. 1994, França et al. 1998, De Gendt et al. 2004). This differs from the situation reported in different fish species. For instance, in juvenile testes containing only spermatogonia, androgen treatment stimulated rapid spermatogonial proliferation both in tissue culture experiments (Miura et al. 1991) and in vivo (Cavaco et al. 1998). However, it was not known if, after the first (pubertal) wave of spermatogenesis, also spermatogonial proliferation during adult spermatogenesis depends on androgens. In mice, for example, more androgen is required for the first than for subsequent waves of spermatogenesis (Handelsman et al. 1999). The present study shows that oestrogen-induced androgen insufficiency reduced proliferation of type A spermatogonia as well as their differentiation into type B spermatogonia in adult zebrafish testis, and strongly reduced the number of meiotic and haploid germ cells produced. To our knowledge, this is the first study localizing specific, androgen-dependent germ cell stages during adult spermatogenesis in teleost fish. This observation correlates well with both the high level of ar mRNA expression in Sertoli cells contacting type A spermatogonia in zebrafish testis (De Waal et al. 2008) and the elevation of circulating androgen levels in Chinook salmon at the time when seasonal spermatogonial proliferation starts (Campbell et al. 2003).

\section{Declaration of interest}

The authors declare there is no conflict of interest that could have prejudiced the impartiality of the research reported.

\section{Funding}

The present study was supported by an intramural $\mathrm{PhD}$ grant of the Utrecht University (The Netherlands), CAPES (Brazil), Fundación Ramón Areces (Spain), the National Institute of Health (grant number DK69711 to J B), and the Erasmus program of the European Union.

\section{Acknowledgements}

The authors would like to acknowledge the following people for their contribution to the work: Wytske van Dijk (Endocrinology and Metabolism) for technical assistance, Henk Schriek and Ko van Rootselaar (Aquarium Facility) for assistance during the in vivo experiments and maintaining the zebrafish stocks, and Roland Romijn and Wieger Hemrika (U-Protein Express BV, Utrecht, The Netherlands) for assistance in expression and purification of recombinant zebrafish Lh.

\section{References}

Akingbemi BT, Ge R, Rosenfeld CS, Newton LG, Hardy DO, Catterall JF, Lubahn DB, Korach KS \& Hardy MP 2003 Estrogen receptor- $\alpha$ gene deficiency enhances androgen biosynthesis in the mouse Leydig cell. Endocrinology 144 84-93.

Andersen L, Goto-Kazeto R, Trant JM, Nash JP, Korsgaard B \& Bjerregaard P 2006 Short-term exposure to low concentrations of the synthetic androgen methyltestosterone affects vitellogenin and steroid levels in adult male zebrafish (Danio rerio). Aquatic Toxicology 76 343-352.

Arukwe A 2008 Steroidogenic acute regulatory (StAR) protein and cholesterol side-chain cleavage (P450scc)-regulated steroidogenesis as an organ-specific molecular and cellular target for endocrine disrupting chemicals in fish. Cell Biology and Toxicology 24 527-540.

Banerjee A \& Khan IA 2008 Molecular cloning of FSH and LH $\beta$ subunits and their regulation by estrogen in Atlantic croaker. General and Comparative Endocrinology 155 827-837.

Baron D, Fostier A, Breton B \& Guiguen Y 2005 Androgen and estrogen treatments alter steady state messengers RNA (mRNA) levels of testicular steroidogenic enzymes in the rainbow trout, Oncorhynchus mykiss. Molecular Reproduction and Development 71 471-479.

Bartke A, Williams KI \& Dalterio S 1977 Effects of estrogens on testicular testosterone production in vitro. Biology of Reproduction 17 645-649.

Van den Belt K, Berckmans P, Vangenechten C, Verheyen R \& Witters H 2004 Comparative study on the in vitro/in vivo estrogenic potencies of $17 \beta$-estradiol, estrone, $17 \alpha$-ethynylestradiol and nonylphenol. Aquatic Toxicology 66 183-195.

Billard R \& Peter RE 1977 Gonadotropin release after implantation of antiestrogens in the pituitary and hypothalamus of goldfish Carassius auratus. General and Comparative Endocrinology 32 213-220.

Blum JL, Nyagode BA, James MO \& Denslow ND 2008 Effects of the pesticide methoxychlor on gene expression in the liver and testes of the male largemouth bass (Micropterus salmoides). Aquatic Toxicology 86 459-469.

Bouma J \& Nagler JJ 2001 Estrogen receptor- $\alpha$ protein localization in the testis of the rainbow trout (Oncorhynchus mykiss) during different stages of the reproductive cycle. Biology of Reproduction $\mathbf{6 5}$ 60-65.

Campbell B, Dickey JT \& Swanson P 2003 Endocrine changes during onset of puberty in male spring Chinook salmon, Oncorhynchus tshawytscha. Biology of Reproduction 69 2109-2117.

Cavaco JE, Vilrokx C, Trudeau VL, Schulz RW \& Goos HJ 1998 Sex steroids and the initiation of puberty in male African catfish (Clarias gariepinus). American Journal of Physiology 275 R1793-R1802.

Chaves-Pozo E, Liarte S, Vargas-Chacoff L, Garcia-Lopez Á, Mulero V, Meseguer J, Mancera JM \& Garcia-Ayala A 2007 17 $\beta$-estradiol triggers postspawning in spermatogenically active gilthead seabream (Sparus aurata L.) males. Biology of Reproduction 76 142-148.

Chieffi P, Colucci-D'Amato GL, Staibano S, Franco R \& Tramontano D 2000 Estradiol-induced mitogen-activated protein kinase (extracellular signalregulated kinase 1 and 2) activity in the frog (Rana esculenta) testis. Journal of Endocrinology 167 77-84.

Choi CY \& Habibi HR 2003 Molecular cloning of estrogen receptor $\alpha$ and expression pattern of estrogen receptor subtypes in male and female goldfish. Molecular and Cellular Endocrinology 204 169-177.

Christianson-Heiska I, Wahteristo P, Kastilan EL, Bergelin E, Bylund G \& Isomaa B 2004 Effects of the wood extractive betulinol and $17 \beta$-oestradiol on reproduction in zebrafish, Danio rerio (Hamilton) - complications due to a bacterial infection. Journal of Fish Diseases 27 267-276.

Cobellis G, Pierantoni R, Minucci S, Pernas-Alonso R, Meccariello R \& Fasano S 1999 c-fos activity in Rana esculenta testis: seasonal and estradiolinduced changes. Endocrinology $1403238-3244$.

Dickey JT \& Swanson P 1998 Effects of sex steroids on gonadotropin (FSH and LH) regulation in coho salmon (Oncorhynchus kisutch). Journal of Molecular Endocrinology 21 291-306.

Eddy EM, Washburn TF, Bunch DO, Goulding EH, Gladen BC, Lubahn DB \& Korach KS 1996 Targeted disruption of the estrogen receptor gene in male mice causes alteration of spermatogenesis and infertility. Endocrinology 137 4796-4805. 
Elizur A 2009 The KiSS1/GPR54 system in fish. Peptides 30 164-170.

Filby AL \& Tyler CR 2005 Molecular characterization of estrogen receptors 1 , $2 \mathrm{a}$, and $2 \mathrm{~b}$ and their tissue and ontogenic expression profiles in fathead minnow (Pimephales promelas). Biology of Reproduction 73 648-662.

Filby AL, Thorpe KL \& Tyler CR 2006 Multiple molecular effect pathways of an environmental oestrogen in fish. Journal of Molecular Endocrinology 37 121-134.

França LR, Parreira GG, Gates RJ \& Russell LD 1998 Hormonal regulation of spermatogenesis in the hypophysectomized rat: quantitation of germ-cell population and effect of elimination of residual testosterone after long-term hypophysectomy. Journal of Andrology 19 335-340.

De la Fuente R, Parra MT, Viera A, Calvente A, Gomez R, Suja JA, Rufas JS \& Page J 2007 Meiotic pairing and segregation of achiasmate sex chromosomes in eutherian mammals: the role of SYCP3 protein. PLoS Genetics 3 e198.

Fukuzawa NH, Ohsako S, Wu Q, Sakaue M, Fujii-Kuriyama Y, Baba T \& Tohyama C 2004 Testicular cytochrome P450scc and LHR as possible targets of 2,3,7,8-tetrachlorodibenzo-p-dioxin (TCDD) in the mouse. Molecular and Cellular Endocrinology 221 87-96.

De Gendt K, Swinnen JV, Saunders PT, Schoonjans L, Dewerchin M, Devos A, Tan K, Atanassova N, Claessens F, Lecureuil C et al. 2004 A Sertoli cellselective knockout of the androgen receptor causes spermatogenic arrest in meiosis. PNAS 101 1327-1332.

Gould ML, Hurst PR \& Nicholson HD 2007 The effects of oestrogen receptors $\alpha$ and $\beta$ on testicular cell number and steroidogenesis in mice. Reproduction 134 271-279.

Govoroun M, McMeel OM, Mecherouki H, Smith TJ \& Guiguen Y 2001 $17 \beta$-estradiol treatment decreases steroidogenic enzyme messenger ribonucleic acid levels in the rainbow trout testis. Endocrinology 142 1841-1848.

Halm S, Martinez-Rodriguez G, Rodriguez L, Prat F, Mylonas CC, Carrillo M \& Zanuy S 2004 Cloning, characterization, and expression of three oestrogen receptors (ER $\alpha, E R \beta 1$ and $E R \beta 2)$ in the European sea bass, Dicentrarchus labrax. Molecular and Cellular Endocrinology 223 63-75.

Handelsman DJ, Spaliviero JA, Simpson JM, Allan CM \& Singh J 1999 Spermatogenesis without gonadotropins: maintenance has a lower testosterone threshold than initiation. Endocrinology 140 3938-3946.

Hawkins MB, Thornton JW, Crews D, Skipper JK, Dotte A \& Thomas P 2000 Identification of a third distinct estrogen receptor and reclassification of estrogen receptors in teleosts. PNAS 97 10751-10756.

Hess RA, Bunick D, Lubahn DB, Zhou Q \& Bouma J 2000 Morphologic changes in efferent ductules and epididymis in estrogen receptor- $\alpha$ knockout mice. Journal of Andrology 21 107-121.

Huggard-Nelson DL, Nathwani PS, Kermouni A \& Habibi HR 2002 Molecular characterization of LH- $\beta$ and FSH- $\beta$ subunits and their regulation by estrogen in the goldfish pituitary. Molecular and Cellular Endocrinology 188 171-193.

Ito K, Mochida K \& Fujii K 2007 Molecular cloning of two estrogen receptors expressed in the testis of the Japanese common goby, Acanthogobius flavimanus. Zoological Science 24 986-996.

Jong FH, Uilenbroek J \& Molen HJ 1975 Oestradiol-17 $\beta$, testosterone and gonadotrophins in oestradiol-17 $\beta$-treated intact adult male rats. Journal of Endocrinology 65 281-282.

Jukosky JA, Watzin MC \& Leiter JC 2008 The effects of environmentally relevant mixtures of estrogens on Japanese medaka (Oryzias latipes) reproduction. Aquatic Toxicology 86 323-331.

Kah O, Trudeau VL, Sloley BD, Chang JP, Dubourg P, Yu KL \& Peter RE 1992 Influence of GABA on gonadotrophin release in the goldfish. Neuroendocrinology 55 396-404.

Kinnberg K \& Toft G 2003 Effects of estrogenic and antiandrogenic compounds on the testis structure of the adult guppy (Poecilia reticulata). Ecotoxicology and Environmental Safety 54 16-24.

Kobayashi M, Sohn YC, Yoshiura Y \& Aida K 2001 Effects of sex steroids on the mRNA levels of gonadotropin subunits in juvenile and ovariectomized goldfish Carassius auratus. Fisheries Science 66 223-231.
Leal MC, Skaar KS, França LR \& Schulz RW 2006 The effects of IGF-I on zebrafish testis in tissue culture. Animal Reproduction: Proceedings of the International Symposium on Animal Biology of Reproduction, Nov. 15-18, 2006, Belo Horizonte, MG, Brazil 3181

Leal MC, de Waal PP, García-López Á, Chen SX, Bogerd J \& Schulz RW $2009 a$ Zebrafish primary testis tissue culture: an approach to study testis function ex vivo. General and Comparative Endocrinology 162 134-138.

Leal MC, Cardoso ER, Nóbrega RH, Batlouni SR, Bogerd J, França LR \& Schulz RW 2009b Histological and stereological evaluation of zebrafish (Danio rerio) spermatogenesis with an emphasis on spermatogonial generations. Biology of Reprododuction (in press: DOI 10.1095/biolreprod.109.076299).

Lin SW \& Ge W 2009 Differential regulation of gonadotropins (FSH and LH) and growth hormone $(\mathrm{GH})$ by neuroendocrine, endocrine, and paracrine factors in the zebrafish - an in vitro approach. General and Comparative Endocrinology 160 183-193.

Lindzey J, Wetsel WC, Couse JF, Stoker T, Cooper R \& Korach KS 1998 Effects of castration and chronic steroid treatments on hypothalamic gonadotropin-releasing hormone content and pituitary gonadotropins in male wild-type and estrogen receptor- $\alpha$ knockout mice. Endocrinology 139 4092-4101.

Liu X, Zhu P, Sham KW, Yuen JM, Xie C, Zhang Y, Liu Y, Li S, Huang X, Cheng $\mathrm{CH}$ et al. 2009 Identification of a membrane estrogen receptor in zebrafish with homology to mammalian GPR 30 and its high expression in early germ cells of the testis. Biology of Reproduction (in press:

DOI 10.1095/biolreprod.108.070250).

Loomis AK \& Thomas P 2000 Effects of estrogens and xenoestrogens on androgen production by Atlantic croaker testes in vitro: evidence for a nongenomic action mediated by an estrogen membrane receptor. Biology of Reproduction 62 995-1004.

Manna PR, Wang XJ \& Stocco DM 2003 Involvement of multiple transcription factors in the regulation of steroidogenic acute regulatory protein gene expression. Steroids $\mathbf{6 8} 1125-1134$.

Meier S, Andersen TE, Norberg B, Thorsen A, Taranger GL, Kjesbu OS, Dale R, Morton HC, Klungsoyr J \& Svardal A 2007 Effects of alkylphenols on the reproductive system of Atlantic cod (Gadus morhua). Aquatic Toxicology 81 207-218.

Menuet A, Pellegrini E, Anglade I, Blaise O, Laudet V, Kah O \& Pakdel F 2002 Molecular characterization of three estrogen receptor forms in zebrafish: binding characteristics, transactivation properties, and tissue distributions. Biology of Reproduction 66 1881-1892.

Minucci S, Di Matteo L, Chieffi P, Pierantoni R \& Fasano S 1997 17ßestradiol effects on mast cell number and spermatogonial mitotic index in the testis of the frog, Rana esculenta. Journal of Experimental Zoology 278 93-100.

Miura T, Yamauchi K, Takahashi H \& Nagahama Y 1991 Hormonal induction of all stages of spermatogenesis in vitro in the male Japanese eel (Anguilla japonica). PNAS 88 5774-5778.

Miura T, Miura C, Ohta T, Nader MR, Todo T \& Yamauchi K 1999 Estradiol-17 $\beta$ stimulates the renewal of spermatogonial stem cells in males. Biochemical and Biophysical Research Communications 264 230-234.

Miura T, Ohta T, Miura CI \& Yamauchi K 2003 Complementary deoxyribonucleic acid cloning of spermatogonial stem cell renewal factor. Endocrinology 144 5504-5510.

Nielsen L \& Baatrup E 2006 Quantitative studies on the effects of environmental estrogens on the testis of the guppy, Poecilia reticulata. Aquatic Toxicology 80 140-148.

O’Donnell L, McLachlan RI, Wreford NG \& Robertson DM 1994 Testosterone promotes the conversion of round spermatids between stages VII and VIII of the rat spermatogenic cycle. Endocrinology 135 2608-2614.

Pawlowski S, van Aerle R, Tyler CR \& Braunbeck T 2004 Effects of $17 \alpha$-ethinylestradiol in a fathead minnow (Pimephales promelas) gonadal recrudescence assay. Ecotoxicology and Environmental Safety 57 330-345.

Pierantoni R, Varriale B, Minucci S, Di Matteo L, Fasano S, D’Antonio M \& Chieffi G 1986 Regulation of androgen production by frog (Rana esculenta) testis: an in vitro study on the effects exerted by estradiol, $5 \alpha$ dihydrotestosterone, testosterone, melatonin, and serotonin. General and Comparative Endocrinology 64 405-410. 
Schulz RW, van der Corput L, Janssen-Dommerholt C \& Goos HJT 1994 Sexual steroids during puberty in male African catfish (Clarias gariepinus): serum levels and gonadotropin-stimulated testicular secretion in vitro. Journal of Comparative Physiology. B, Biochemical, Systemic, and Environmental Physiology 164 195-205.

Schwartz JR \& Roy SK 2000 Expression of P450 side-chain cleavage (CYP11A1) and P450 17 $\alpha$-hydroxylase-17/20 lyase (CYP17) messenger ribonucleic acid in hamster primary interstitial cells in vitro: differential regulation of steroidogenesis by cyclic adenosine monophosphate. Biology of Reproduction 63 503-507.

Sohn YC, Yoshiura Y, Kobayashi M \& Aida K 1998 Effect of sex steroids on the mRNA levels of gonadotropin I and II subunits in the goldfish Carassius auratus. Fisheries Science 64 715-721.

Song M \& Gutzeit HO 2003 Effect of 17- $\alpha$-ethynylestradiol on germ cell proliferation in organ and primary culture of medaka (Oryzias latipes) testis. Development, Growth and Differentiation 45 327-337.

Tsai PS, Kessler AE, Jones JT \& Wahr KB 2005 Alteration of the hypothalamicpituitary-gonadal axis in estrogen- and androgen-treated adult male leopard frog, Rana pipiens. Reproductive Biology and Endocrinology 32.

Turner KJ, Morley M, Atanassova N, Swanston ID \& Sharpe RM 2000 Effect of chronic administration of an aromatase inhibitor to adult male rats on pituitary and testicular function and fertility. Journal of Endocrinology 164 225-238.

Van der Ven LT, Wester PW \& Vos JG 2003 Histopathology as a tool for the evaluation of endocrine disruption in zebrafish (Danio rerio). Environmental Toxicology and Chemistry 22 908-913.

Van der Ven LT, van den Brandhof EJ, Vos JH \& Wester PW 2007 Effects of the estrogen agonist $17 \beta$-estradiol and antagonist tamoxifen in a partial life-cycle assay with zebrafish (Danio rerio). Environmental Toxicology and Chemistry 26 92-99.

De Waal PP, Wang DS, Nijenhuis WA, Schulz RW \& Bogerd J 2008 Functional characterization and expression analysis of the androgen receptor in zebrafish (Danio rerio) testis. Reproduction 136 225-234.

Weber LP, Balch GC, Metcalfe CD \& Janz DM 2004 Increased kidney, liver, and testicular cell death after chronic exposure to $17 \alpha$-ethinylestradiol in medaka (Oryzias latipes). Environmental Toxicology and Chemistry 23 792-797.

Westerfield M 2000 The Zebrafish Book. A Guide for the Laboratory use of Zebrafish (Danio rerio). 4th edn, Eugene: Univ. of Oregon Press.

Wu C, Patino R, Davis KB \& Chang X 2001 Localization of estrogen receptor $\alpha$ and $\beta$ RNA in germinal and nongerminal epithelia of the channel catfish testis. General and Comparative Endocrinology 124 12-20.

Zhang X, Hecker M, Park JW, Tompsett AR, Newsted J, Nakayama K, Jones PD, Au D, Kong R, Wu RS et al. 2008 Real-time PCR array to study effects of chemicals on the hypothalamic-pituitary-gonadal axis of the Japanese medaka. Aquatic Toxicology 88 173-182.

Zhou Q, Nie R, Prins GS, Saunders PT, Katzenellenbogen BS \& Hess RA 2002 Localization of androgen and estrogen receptors in adult male mouse reproductive tract. Journal of Andrology 23 870-881.

Received in final form 23 April 2009
Accepted 5 May 2009

Made available online as an Accepted Preprint 5 May 2009 